\title{
The impact of fathers' physical and psychosocial work conditions on attempted and completed suicide among their children Ostry Aleck*1, Maggi Stefania ${ }^{2}$, Tansey James ${ }^{3}$, Dunn James ${ }^{4}$, Hershler Ruth ${ }^{1}$, Chen Lisa ${ }^{1}$, Louie Amber ${ }^{1}$ and Hertzman Clyde ${ }^{1}$
}

\author{
Address: ${ }^{1}$ Department of Health Care and Epidemiology, University of British Columbia, Vancouver, Canada, ${ }^{2}$ University College of the Cariboo- \\ Thompson Rivers University, Kamloops, Canada, ${ }^{3}$ Oxford University, Oxford, UK and ${ }^{4}$ University of Toronto, Toronto, Canada \\ Email: Ostry Aleck* - ostry@interchange.ubc.ca; Maggi Stefania - smaggi@tru.ca; Tansey James - james.tansey@sbs.ox.ac.uk; \\ Dunn James - jim.dunn@utoronto.ca; Hershler Ruth - hershler@interchange.ubc.ca; Chen Lisa - lisachen@interchange.ubc.ca; \\ Louie Amber - ammlouie@interchange.ubc.ca; Hertzman Clyde - clyde.hertzman@ubc.ca \\ * Corresponding author
}

Published: 27 March 2006

BMC Public Health2006, 6:77 doi:10.1 186/147|-2458-6-77
Received: 06 December 2005

Accepted: 27 March 2006

This article is available from: http://www.biomedcentral.com/I47I-2458/6/77

C 2006 Aleck et al; licensee BioMed Central Ltd.

This is an Open Access article distributed under the terms of the Creative Commons Attribution License (http://creativecommons.org/licenses/by/2.0), which permits unrestricted use, distribution, and reproduction in any medium, provided the original work is properly cited.

\begin{abstract}
Background: Adverse employment experiences, particularly exposure to unemployment and the threat of unemployment, have been strongly associated with several adverse mental and physical health outcomes including suicide. However, virtually no research has been conducted on the trans-generational impact of parental working conditions on attempted or completed suicide among their children.
\end{abstract}

Methods: We conducted a nested case control study based on a cohort, gathered in the western Canadian province of British Columbia, of male sawmill workers and a second cohort of their children. Physical and psychosocial work conditions to which fathers were exposed during the first 16 years of their children's lives, measured using the demand/control model, were linked to hospital suicide records (attempted and completed) among their children.

Results: Two hundred and fifty children in the cohort attempted or committed suicide between 1985 and 200I. Multivariate models, with partial control for father's mental health outcomes prior to their child's suicide demonstrate, I) a strong association between low duration of father's employment at a study sawmill and attempted suicide for their male children, 2) elevated odds for attempted suicide among female children of fathers' employed in a sawmill job with low control and, 3) a strong association between fathers in jobs with low psychological demand and completed suicides among male children.

Conclusion: Exposure of fathers to adverse psychosocial work conditions during the first 16 years of their children's life was associated with greater odds for attempted and completed suicide among their children.

\section{Background}

Adverse employment experiences, particularly exposure to unemployment and the threat of unemployment, have been associated with a range of adverse mental and physical health outcomes [1-3] including suicide [4-6]. However, virtually no research has been conducted on the 
trans-generational impact on the health of their children of adverse parental working conditions.

Exposures to varying socio-economic circumstances, during childhood and beyond, constitutes a unique "life exposure trajectory," which will manifest as different expressions of health and well-being over the life-course [7]. The possible long-term exposure/expression relationships can be conceptualized in three generic models: latency, cumulative, and pathway. Latency refers to relationships between an exposure at one point in the life course and a health outcome years or decades later, irrespective of intervening experience. Cumulative refers to multiple exposures over the life course whose effects on health combine. These may be either multiple exposures to a single recurrent factor (e.g., chronic poverty) or a series of exposures to different factors. Finally, pathways are dependent sequences in which an exposure at one stage of the life course influences the probability of other exposures later in the life course, which are the proximate causes of disease expression [7-13].

While this framework is useful to describe the biological mechanism by which the impacts of adverse family socioeconomic environments might act to affect the health of children, it tells us little about which dimensions of family socio-economic environment may be most salient.

Research conducted over the past 75 years has shown that parental access to employment (or lack thereof) directly impacts the psychological health, behaviour, and educational outcomes of their children likely through the "sequential effects on parents' job-related affect and parenting behaviours" [14-17].

In order to test the possibility that exposure of parents to adverse employment conditions may impact their children's mental health status, unusual data sets are required which bring together occupational exposure information for the parent(s) and mental health outcome data for their children. Over the past 15 years we have gathered a cohort of approximately 30,000 sawmill workers in British Columbia (BC) and a second cohort consisting of their children with the appropriate data elements in place to conduct this type of study. The purpose of this paper is investigate the impact of fathers' psychosocial and physical work conditions during the first 16 years of their children's life on attempted and completed suicides among their children, during childhood through to middle-adulthood.

Individuals exposed to adverse socio-economic circumstances during childhood tend to be less healthy later in life compared to individuals who experienced a more advantaged childhood. This relationship appears consist- ent in well-designed longitudinal studies across many physical health outcomes into adulthood (e.g., selfreported health, coronary heart disease, body mass index, and other chronic conditions) [18-24]. These results also hold for a range of psychological and behavioural outcomes $[18,25]$. And, the way in which such exposures in childhood might manifest in later adverse health outcomes has biological plausibility [7].

In a literature originating in the Great Depression of the 1930 s and continuing through to the present, adverse family income and employment circumstances have been linked to negative mental health, behavioural, and physical health outcomes among children. Several studies have shown that major family income losses between 1929 and 1933 increased the emotional instability of fathers but not mothers $[26,27]$. These studies indicate that male reaction to income loss was increased anger and a tendency for fathers to be punitive and arbitrary when disciplining their children $[14,15,28]$.

After a hiatus of five decades, several American and Canadian studies were conducted on the impacts of family job insecurity on children's mental health outcomes and school-related problems [16,17]. Most of this research identified an association between father's punishing and rejecting behaviours and adverse school behaviours and academic outcomes among their children [29,30]. A number of researchers have further postulated that parental punishing behaviour predicts externalizing behaviours (i.e., anger-based acting out behaviours) in their children whereas parental rejecting behaviours predict internalized symptoms (i.e. depression and anxiety) [31].

Only one study was found that explored the link between the psychosocial work conditions experienced by employed fathers and outcomes among their children. In this Canadian study, conducted among 189 grade 4 and 5 students, utilizing Karasek's demand/control model, Stewart and Barling [17] demonstrated that fathers psychosocial conditions at work influenced their parenting behaviours, which in turn affected their children's' behaviour.

These studies indicate first, that father's work may have a greater influence on children's behaviour and educational and health outcomes than mother's work. Second, they indicate that the potential pathway linking father's work conditions to their children's health may be through altered parenting behaviour, in particular, more disciplining and authoritarian behaviours meted out to children when fathers come under pressure at work.

The present study investigates the impact of fathers' psychosocial and physical work conditions on attempted and 
completed suicides in a cohort of children residing mainly in rural forest-industry dependent communities in the province of British Columbia in Western Canada.

\section{Methods}

This study is based on a cohort of male sawmill workers for whom we have obtained data on their history of unemployment and physical and psychosocial work conditions. Using birth files from the provincial vital statistics registry, we developed a second cohort consisting of most of their children. This cohort was linked to the BC Linked Health Database (BCLHDB) in order to obtain attempted and completed suicide outcomes. Ethical approval was obtained from the University of British Columbia and the BC Ministry of Health to conduct this study.

\section{A) The original cohort}

The original cohort was gathered in order to conduct an occupational study on the effects of chlorophenol antisapstain exposure among BC sawmill workers. We identified 14 sawmills located in $\mathrm{BC}$ and accessed personnel records for workers who had worked, for at least one year, in one of these mills anytime between 1950 and 1998. The cohort consists of 28,794 males. Personal identifying information for eligible workers and complete job history records were abstracted from personnel records (See Hertzman et al. [32] for a complete description of methods used to assemble this cohort).

\section{B) Exposure assessment}

From the job history records we obtained the number of episodes of unemployment, job mobility (classified as upward, downward or stable), and occupation (manager, skilled trades, machine operator, or unskilled). We obtained historical estimates of job control, demands, noise, and social support in two ways: 1) 4 experienced job evaluators (two union and two management) in the BC sawmill industry filled out the demand/control questionnaire to obtain a retrospective estimation for all basic job titles prior to 1975 (See Ostry, Marion, \& Green et al. [33], for these methods); 2) a panel of senior workers was selected in each mill and filled out Karasek's questionnaire for basic job titles in their mill for two time periods (1975 to 1985), (1985 to 1998) (See Ostry, Marion \& Green et al. [34], for these methods). These expert estimates for control, psychological demand, physical demand, social support, and noise were then applied to the job history database in the fathers' cohort.

\section{C) The children's cohort}

The cohort of adult sawmill workers was linked to the BC birth file in order to identify all of the children of these workers born in British Columbia between 1952 and 2000 (see Dimich-Ward et al. [35] for these methods). There were 37, 827 children in the cohort of whom 19,833 satisfied our eligibility criteria (i.e. father had at least one year of work in a study sawmill while their child or children were aged $0-16$ ).

\section{D) The dependent variables}

Using probabilistic linkage techniques the children's cohort was linked to the $\mathrm{BC}$ Linked Health Database (BCLHDB), consisting of person-specific, longitudinal records on all British Columbians (see Hertzman et al. [32] for these methods. We were able to link 88 percent of the members of the children's cohort to the BCLHDB. These files contain data on deaths, hospital discharges, and other medical encounters for the years 1985 through to 2001. The records are stored separately but have been indexed with an individual service-recipient-specific code so that the records of groups of individuals can be linked across files for specific research projects.

A Data Access Subcommittee consisting of health ministry personnel, staff from the BC Ministry of Information and Privacy, and the Centre for Health Services and Policy Research has been established to handle requests for linkage to the BCLHDB and to ensure that such requests meet scientific and ethical standards, are in the public interest, and conform with the Freedom on Information and Protection of Privacy Act.

Using ICD9 codes available in the hospital discharge database we were able to identify any suicide case (completed and attempted) that occurred between Jan 1985 and March 31st, 2001. A suicide case was defined as anyone with a hospital discharge or death record coded with ICD9 code 950 to 950.9 .

\section{E) Building the exposure file}

We determined children's exposure to adverse family socio-economic circumstances by applying father's expo-

Table I: Attempted and completed suicides by gender among members of the children's cohort from I985 to 200 I

\begin{tabular}{|c|c|c|c|c|}
\hline Suicides & Male & Female & Unknown gender & Total \\
\hline Completed & $20(77 \%) *$ & $4(15 \%)$ & $2(8 \%)$ & $26(100)$ \\
\hline Attempted & $81(35.8 \%)$ & $145(64.2 \%)$ & & $226(100)$ \\
\hline Total & $101(40.1)$ & $149(59.1)$ & $2(0.8)$ & $252(100)$ \\
\hline
\end{tabular}

* Numbers in parentheses are row percents 
Table 2: Socio-demographic and occupational characteristics of the fathers of case and control children

\begin{tabular}{|c|c|c|c|c|}
\hline Independent Variables & $\begin{array}{l}\text { Attempted } \\
\text { Suicides }\end{array}$ & & $\begin{array}{l}\text { Completed } \\
\text { Suicides }\end{array}$ & \\
\hline & Cases & Controls & Cases & Controls \\
\hline \multicolumn{5}{|l|}{ Father's Marital Status } \\
\hline$\%$ Unmarried $(\mathrm{N})$ & $13.9(29)$ & $8.0(50)$ & $12.5(3)$ & $8.0(6)$ \\
\hline \% Married (N) & $86.1(179)$ & $92.0(572)$ & $87.5(2 \mathrm{I})$ & $92.0(69)$ \\
\hline \multicolumn{5}{|l|}{ Father's Ethnicity } \\
\hline \% Caucasian $(\mathrm{N})$ & 88.1 (199) & $85.3(578)$ & $88,5(23)$ & $69.2(54)$ \\
\hline$\% \operatorname{Sikh}(\mathrm{N})$ & $10.6(24)$ & $13.3(90)$ & $11.5(3)$ & $25.6(20)$ \\
\hline \% Chinese or Other Asian (N) & $1.3(3)$ & $1.5(10)$ & 0 & $5.1(4)$ \\
\hline \multicolumn{5}{|l|}{ Father's Occupational Status } \\
\hline$\%$ Manager $(\mathrm{N})$ & $6.2(14)$ & $6.9(47)$ & $3.8(1)$ & $5.1(4)$ \\
\hline$\%$ Tradesman $(\mathrm{N})$ & $30.1(68)$ & $34.5(234)$ & $26.9(7)$ & $39.7(31)$ \\
\hline \% Skilled (N) & $17.7(40)$ & $19.8(134)$ & $30.8(8)$ & $19.2(15)$ \\
\hline \% Unskilled (N) & $46.0(104)$ & $38.8(263)$ & $38.5(10)$ & $35.9(28)$ \\
\hline Father's average duration (years) of employment at sawmill (sd) & $5.7(4.1)$ & $6.8(4.1)$ & $5.8(3.9)$ & $7.9(3.9)$ \\
\hline Father's average \# of episodes of unemployment (sd) & $1.05(1.2)$ & $1.12(1.3)$ & $1.08(1.23)$ & $1.14(1.34)$ \\
\hline
\end{tabular}

sure (in terms of job mobility, unemployment experience, and exposure to control, psychological demand, physical demand, social support, and noise) during each year of the child's life from age zero to the end of their 16th birthday.

\section{F) Case control analysis}

Cases were identified for each completed and attempted suicide. Using survival-time to case-control on STATA 8.0, three controls were selected for each case matched on age and gender. Controls were chosen randomly with replacement from the set at risk. The set at risk were all the children in the cohort, born between 1952 and 1998, whose father worked in a study sawmill for at least one year during the first $0-16$ years of the child's life. These could be anyone at risk who also satisfied the matching criteria who had not attempted suicide at the time of diagnosis of the case.

Other socio-demographic characteristics of father's that were available in the cohort database and, potentially of importance in relation to children's suicides, were father's marital status (married, divorced, widowed, or single) and race (East-Indian, Chinese and other). As well, we were able to determine, from the BCLHDB, whether a father had a completed or attempted suicide, mental health diagnosis, or alcohol-related mental health diagnosis, prior to their child's attempted or completed suicide.

Statistical analyses were conducted using conditional logistic regression on STATA 8.0. Univariate models were first run with each independent variable. Multivariate models were developed in three steps. Father's sociodemographic characteristics were controlled for in model 1 . In the second step, father's suicide, mental health diag- nosis, or alcohol-related mental health diagnosis prior to their child's suicide attempts or completion were controlled. Fathers' occupation at the time prior to their child's suicide was added to the final model.

\section{Results}

Of the 19,833 children in the cohort, 252 attempted or committed suicide between 1985 and 2001 (Table 1). Approximately three quarters of children completing suicide were male whereas approximately two-thirds of children attempting suicide were female. More children of unmarried fathers attempted and completed suicide compared to children of married fathers and, more children of Caucasian fathers attempted or completed suicide compared to children of non-Caucasian fathers (Table 2).

For male and female children, univariate results show that father's marital and ethnic status was not associated with attempted suicide. For males, father's prior diagnosis for an alcohol-related mental health condition was associated with elevated odds for their child's attempted suicide. For females, father's prior diagnosis for a mental health condition was associated with elevated odds for attempted suicide (Table 3).

Additionally, for males, father's employment in an unskilled sawmill job prior to their child's suicide was associated with increased odds for their child's attempted suicide. Lower duration of employment at a sawmill was also associated with elevated odds for attempted suicide for male children. Univariate analyses demonstrated that fathers' lower duration of employment at a sawmill, low control and high physical demand were also associated with elevated odds for attempted suicide among female children. Univariate analyses also demonstrated that male 
Table 3: Univariate models for attempted suicides among children of sawmill workers during the first 16 years of the child's life.

\begin{tabular}{|c|c|c|}
\hline Independent Variables & Males & Females \\
\hline \multicolumn{3}{|l|}{ Father's ethnicity (ref = Caucasian) } \\
\hline Sikh & $.42(.16,1.12)^{*}(.08)^{* *}$ & $1.0(.58,1.73)(1.0)$ \\
\hline Chinese & $1.0(.10, .88,1.14)(.95)$ & $.85(.17,4.31)(.84)$ \\
\hline Father's marital status (ref $=$ married) & $1.00(.88,1.14)(.95)$ & $.97(.88,1.07)(.52)$ \\
\hline Father's suicide attempt $* * * *$ & $3.0(.61,14.86)(.18)$ & - \\
\hline Father's mental health diagnosis & $\mathrm{I} .42(.79,2.57)(.24)$ & $1.97(1.19,3.25)(.01)$ \\
\hline Father's alcohol diagnosis & $3.75(1.00,13.96)(.05)$ & $1.5(.45,4.98)(.51)$ \\
\hline \multicolumn{3}{|l|}{ Father's Occupational Status (ref = manger) } \\
\hline Tradesman & $.56(.32,1.0)(.05)$ & $.99(.66,1.49)(.96)$ \\
\hline Skilled & $1.0(.52,1.91)(1.0)$ & $.80(.49,1.32)(.39)$ \\
\hline Unskilled & $1.84(1.08,3.14)(.03)$ & $1.17(.79,1.73)(.43)$ \\
\hline Father's average duration (years) of employment at sawmill & $.92(.86, .97)(.00)$ & $.95(.91, .997)(.04)$ \\
\hline Father's average \# of episodes of unemployment & $.92(.75,1.13)(.42)$ & $.97(.84,1.13)(.72)$ \\
\hline \multicolumn{3}{|l|}{ Psychosocial and physical work conditions } \\
\hline Control & $.94(.86,1.02)(.14)$ & $.92(.86, .99)(.03)$ \\
\hline Psychological demand & $.91(.78,1.07)(.27)$ & $.99(.88,1.12)(.86)$ \\
\hline Physical demand & $1.55(.86,2.80)(.14)$ & $1.60(1.00,2.57)(.05)$ \\
\hline Social support & $.88(.59,1.3)(.52)$ & $.95(.70,1.29)(.75)$ \\
\hline Noise & $.80(.46,1.39)(.43)$ & $1.02(.62,1.68)(.93)$ \\
\hline
\end{tabular}

* 95\% Confidence intervals; ${ }^{* *} \mathrm{p}$-value; ***data are missing as no father attempted or completed suicide prior to their female child's suicide attempt.

children of tradesmen had significantly lower odds for attempted suicide relative to other occupations (Table 3 ).

As only 4 female children completed suicide univariate models were not run for female children. For male children, univariate models demonstrated no association between father's socio-demographic status and completed suicide. Further, univariate models showed association with completed suicide except for low psychological demand which was associated with elevated odds for completed suicide $(\mathrm{OR}=0.46 ; \mathrm{CI}=0.26-0.79 ; \mathrm{p}=0.00)$.

Fully controlled multivariate models demonstrate a strong association between low duration of father's employment at a study sawmill and attempted suicide for male children. (Table 4). Fully controlled multivariate models demonstrate that elevated odds for attempted suicide among female children is associated with prior mental health diagnosis for their fathers and employment in a sawmill job with low control (Table 5). Finally, fully controlled models indicate that father's employment in a job with low psychological demand is associated with elevated odds for completed suicides among male children (Table 6).

\section{Discussion}

Four main results arise from this study. First, even after partially controlling for the impact of a father's own his-

Table 4: Multivariate models for attempted suicides among male children of sawmill workers during the first 16 years of the child's life

\begin{tabular}{lccc}
\hline Independent Variables & Model I & Model 2 & Model 3 \\
\hline Father's ethnicity (ref = Caucasian) & & & \\
Sikh & $.55(.20,1.53)^{*}(.25)^{* * *}$ & $.58(.21,1.63)(.30)$ & $.52(.18,1.49)(.22)$ \\
Chinese & $1.05(.11,10.32)(.96)$ & $1.09(.11,10.7)(.94)$ & $1.12(.11,11.47)(.92)$ \\
Father's marital status (ref = married) & $.98(.86,1.11)(.73)$ & $.96(.85,1.1)(.59)$ & $.95(.83,1.08)(.44)$ \\
Father's suicide & & $1.98(.36,10.93)(.43)$ & $1.75(.31,9.94)(.53)$ \\
Father's mental health diagnosis & $1.26(.65,2.45)(.50)$ & $1.26(.65,2.47)(.49)$ \\
Father's alcohol diagnosis & $3.58(.87,14.71)(.08)$ & $3.68(.87,15.50)(.08)$ \\
Father's Occupational Status (ref = manger) & & $1.03(.29,3.69)(.96)$ \\
Tradesman & & $1.48(.41,5.36)(.55)$ \\
Skilled & & $1.83(.55,6.12)(.33)$ \\
Unskilled & & $\mathbf{. 9 3}(.87,1.00)(.05)$
\end{tabular}

* $95 \%$ Confidence intervals; ** p-value. 
Table 5: Multivariate models for attempted suicides among female children of sawmill workers during the first 16 years of the child's life

\begin{tabular}{|c|c|c|c|}
\hline Independent Variables & Model I & Model 2 & Model 3 \\
\hline \multicolumn{4}{|l|}{ Father's ethnicity (ref = Caucasian) } \\
\hline Sikh & $.86(.49,1.54)^{*}(.63)^{* *}$ & $.73(.14,3.77)(.70)$ & $.76(.15,3.96)(.74)$ \\
\hline Chinese & $.85(.13,3.33)(.61)$ & $.73(.14,3.77)(.70)$ & $.76(.15,3.96)(.74)$ \\
\hline Father's marital status (ref $=$ married) & $.96(.87,1.06)(.43)$ & $.97(.87,1.07)(.52)$ & $.96(.87,1.07)(.49)$ \\
\hline \multicolumn{4}{|l|}{ Father's Occupational Status (ref = manger) } \\
\hline Tradesman & & & $.76(.31,1.85)(.54)$ \\
\hline Skilled & & & $.53(.20,1.40)(.20)$ \\
\hline Unskilled & & & $.45(.16,1.22)(.12)$ \\
\hline Father's average duration (years) of employment at sawmill & $.96(.91,1.01)(.09)$ & $.96(.91,1.01)(.10)$ & $.95(.90,1.00)(.06)$ \\
\hline \multicolumn{4}{|l|}{ Psychosocial and physical work conditions } \\
\hline Control & $.95(.88,1.02)(.15)$ & $.95(.88,1.02)(.20)$ & $.90(.81, .99)(.04)$ \\
\hline Physical & $1.31(.77,2.22)(.32)$ & $1.37(.80,2.36)(.25)$ & $\mathrm{I} .5 \mathrm{I}(.82,2.76)(.18)$ \\
\hline Father's suicide $* * *$ & & - & - \\
\hline Father's mental health diagnosis & & $1.95(1.13,3.37)(.02)$ & $2.01(1.16,3.49)(.01)$ \\
\hline Father's alcohol diagnosis & & $.93(.22,3.87)(.92)$ & $.82(.19,3.50)(.79)$ \\
\hline
\end{tabular}

* 95\% Confidence intervals; ** p-value; ***data are missing as no father of a female child who attempted suicide had attempted or completed suicide prior to their child's attempt.

tory of mental health, male children of fathers with low duration of employment at a study sawmill while their child or children were less than age 16 had a greater odds of attempting suicide than children of fathers with high duration of employment. Second, female children of fathers who experienced low job control during the first 16 years of their child's life had significantly greater odds for attempting suicide. Third, after partially controlling for father's history of mental illness and other potential confounders, male children of fathers employed in jobs with low psychological demand showed significantly greater odds for completing suicide.

These results indicate that adverse work conditions for fathers experienced while their children are growing up may have serious psychological outcomes for these chil- dren. This investigation also shows that the impact of fathers' work experience may differ for males and females in relation to attempted suicide. This is consistent with the literature which shows that economic downturns may impact mental health outcomes among children and that the impact may differ for boys and girls [15].

Most of the children in this investigation were resident in small rural resource dependent communities in British Columbia during their childhood. Given that resource dependent communities in British Columbia have been exposed to continuous and intensive restructuring and downsizing since the early 1980s, these children may have been particularly "at risk" for adverse mental health outcomes including suicide. Research from Australia, Norway, and the United Kingdom have found the largest

Table 6: Multivariate model for completed suicides among male children of sawmill workers during the first 16 years of the child's life

\begin{tabular}{|c|c|c|c|}
\hline Independent Variables & Model I & Model 2 & Model 3 \\
\hline \multicolumn{4}{|l|}{ Father's ethnicity (ref = Caucasian) } \\
\hline Sikh & $.37(.04,3.37)^{*}(.38)^{* *}$ & $.33(.04,3.08)(.33)$ & $.36(.03,4.56)(.43)$ \\
\hline Chinese ${ }^{* * *}$ & - & - & - \\
\hline Father's marital status (ref = married) & I.I3 (.78,I.6I) (.52) & $1.13(.76,1.67)(.56)$ & $1.23(.76,1.98)(.40)$ \\
\hline Father's suicide & - & - & - \\
\hline Father's mental health diagnosis & $.11(.01,1.42)(.09$ & $.12(.01,1.42)(.09)$ & $.13(.01,1.47)(.10)$ \\
\hline Father's alcohol diagnosis $* * * *$ & - & - & - \\
\hline \multicolumn{4}{|l|}{ Father's Occupational Status (ref = manger) } \\
\hline Tradesman & & & $.82(.05,13.78)(.89)$ \\
\hline Skilled & & & $3.14(.17,57.56)(.44)$ \\
\hline Father's average duration (years) of employment at sawmill & $.98(.86,1.13)(.82)$ & $.99(.86,1.14)(.89))$ & $.97(.80,1.16)(.71)$ \\
\hline \multicolumn{4}{|l|}{ Psychosocial and physical work conditions } \\
\hline Psychological demand & $.53(.30, .95)(.03)$ & $.40(.18, .90)(.03)$ & $.42(.20, .98)(.04)$ \\
\hline
\end{tabular}

$* 95 \%$ Confidence intervals; $* *$ p-value; $* * *$ data are missing as no Chinese fathers had a male child who completed suicide; $* * * *$ data are missing as no father of a case or control had an alcohol-related mental health diagnosis. 
increases in suicide rates for young adults since the 1970 s occurred among residents in rural regions [36-41].

There are several limitations to this study. First, the literature indicates that an important mediating factor between low family social economic circumstances during childhood and future health status of the children may be father's parenting behaviour. However, much of the evidence (but not all) for this was obtained in studies dating from the 1930s and the 1980s when father's role as breadwinner was more prominent than at present. Today, with female labour force participation rates approaching those of males, it is much more important to understand both mothers and fathers employment circumstances in relation to their children's health.

We have no data on mother's employment circumstances in this study. This limitation may be ameliorated to some extent because the investigation was conducted both historically and in a labour market characterized by fairly "traditional" gender roles. Thus, father's employment conditions were likely, given the context of this particular study, to have in fact been more important than the mothers'.

Second, data on place of residence for children was not available. These analyses assume that children resided with their fathers while he was working at a study mill during his children's first 16 years of life. However, it is quite likely that divorces took place and some of these children were residing with their mothers and therefore under-exposed to adverse paternal work circumstances during their childhood. Given that the socio-economic range within this fairly homogenous group of sawmill workers was fairly narrow it is unlikely that divorce rates differed systematically for cases and controls.

Third, we were able to link 88 percent of the children to the BCLHDB. Most of the 12 percent of children in the cohort who we were unable to link to the BCLHDB were likely younger healthy children who had not yet had contact with hospitals or physicians. Given that very young children are unlikely to attempt or commit children this will not bias our study. However, to the extent that we did not link to older children, because they were healthy enough to have avoided the healthcare system and therefore not be present in the BCLHDB, this could have introduced bias to slightly strengthen the observed associations in this study. Given the relatively high probabilistic linkage efficiency in this study this is likely to be of minimal concern.

Fourth, the study is based on cases admitted to acute-care and to psychiatric hospitals across BC. It does not record admissions for attempted suicide at community treatment facilities. As well, some people who attempted suicide may not present to physicians and may not even acknowledge their attempts to friends and family so that some unknown number of attempted suicides will have been missed in this study. However, given that the mental health care system in the province is heavily weighted towards hospital care, it is likely that only a very few attempted suicides would have been missed.

Fifth, the average age of men in the fathers cohort would have been about 50 years in 1985, the date when information on their mental health outcomes became available. This means that suicide and mental health outcomes that occurred when these men were younger, prior to 1985 , were not recorded. This means that our statistical adjustment for father's suicides, alcohol-related mental health and other mental health outcomes are only partial. Full adjustment for father's mental health status (i.e., adjustment taking account of mental health events going back to father's childhoods) may slightly attenuate the observed associations between psychosocial work conditions and their children's suicide outcomes.

A strength of this investigation arises because of the complex data sets developed including the ability to control, at least partially, for the impact of father's history of mental health prior to an attempted or completed suicide by their child. In order to move these kinds of trans-generational analyses forward, unusual data sets of this type are required.

Furthermore, a full history of employment for fathers would have been ideal for use in this study. We only had father's employment while employed in a study sawmill. But, we applied fathers sawmill employment exposure to a specific window of time during their children's lives (i.e., during their first 16 years). Thus, we have utilized the data in a way that is consistent with the now well developed models of the importance of exposure to adverse socioeconomic conditions early in life. This too is a strength of the analytical approach taken in this investigation.

\section{Conclusion}

Using a unique data set, this investigation builds upon an older literature that has linked paternal exposure to adverse employment conditions during the early stages of their children's lives to adverse mental health outcomes among these children. While this earlier literature focused mainly on paternal exposure to unemployment this investigation has also demonstrated that prolonged exposure of children to adverse paternal psychosocial work conditions may also be implicated in suicide outcomes for these children. 


\section{Abbreviations \\ $\mathrm{BC}=$ British Columbia}

BCLHDB $=$ British Columbia Linked Health Database

ICD = International Classification of Disease

OR = Odds Ratio

$\mathrm{CI}=95 \%$ Confidence Interval

\section{Competing interests}

The author(s) declare that they have no competing interests.

\section{Authors' contributions}

ASO guided the analyses, developed the methods, and drafted the paper. JT helped guide the analysis and aided in writing the paper. SM guided the analysis and aided in writing the paper. JD aided in the analysis RH conducted the analysis. LC conducted the analysis. AML conducted and wrote the literature review. $\mathrm{CH}$ guided the analysis, and developed the methods. All authors read and approved the final manuscript.

\section{Acknowledgements}

This work was funded by the Canadian Population Health Initiative. Dr. Ostry was funded through a new investigator award from the Canadian Institutes for Health Research and holds a scholar award from the Michael Smith Foundation for Health Research in British Columbia. Dr. Maggi is funded through a new investigator award from the Canadian Institutes for Health Research. Dr. Hertzman is holds a Canada Research Chair in Population Health.

\section{References}

I. Karasek R, Theorell T: Healthy work: stress, productivity and the reconstruction of working life New York, Basic Books; 1990.

2. Marmot MG: Social Inequalities in Mortality: the Social Environment. In Class and Health: Research and Longitudinal Data Edited by: Wilkenson RG. London, Tavistock Publications; 1986.

3. Marmot M: The social pattern of health and disease. In Health and social organization Edited by: Blane D, Brunner E and Wilkinson R. London, Routledge; 1996.

4. Lewis G, Sloggett A: Suicide, deprivation, and unemployment: record linkage study. BMJ 1998, 3 I 7:1283-I286.

5. Morton MJ: Prediction of repetition of parasuicide: with special reference to unemployment. Int J Soc Psychiatry 1993, 39:87-99.

6. Platt S: Unemployment and suicidal behaviour: a review of the literature. Social Science and Medicine 1984, I9:93-I I 5.

7. Hertzman C, Wiens M: Child Development and Long-term Outcomes: A Population Health Perspective and Summary of Successful Interventions. Social Science Medicine 1996, 43:1083-1095

8. Hertzman C, Power C: Child development as a determinant of health across the life course. Current Pediatrics 2004, I 4:438-443.

9. Hertzman C, Power C: Health and human development: understandings from life-course research. Dev Neuropsychol 2003, 24:719-744.

10. Hertzman C, Power C, Matthews S, Manor O: Using an interactive framework of society and lifecourse to explain self-rated health in early adulthood. Soc Sci Med 200I, 53:1575-I585.
II. Hertzman C: The biological embedding of early experience and its effects on health in adulthood. Annals of the New York Academy of Sciences 2000, 896:85-95.

12. Jefferis BJ, Power C, Hertzman C: Birth weight, childhood socioeconomic environment, and cognitive development in the I 958 British birth cohort study. BMJ 2002, 325:305.

13. Power C, Hertzman C: Social and biological pathways linking early life and adult disease. Br Med Bull 1997, 53:2 I0-221.

14. Elder G, Liker J, Cross C: Parent-child behavior in the GreatDepression: Life course and intergenerational influences. In Life Span development and behavior Edited by: Baltes P and Brim Jr O. New York, Academic Press; 1984:109-158.

I5. Elder GHJ, Nguyen TV, Caspi A: Linking family hardship to children's lives. Child Dev 1985, 56:361-375.

16. Flanagan CA, Eccles JS: Changes in parents' work status and adolescents' adjustment at school. Child Dev 1993, 64:246-257.

17. Stewart W, Barling J: Fathers' work experiences effect children's behaviors via job-related affect and parenting behaviors. Journal of Organizational Behavior 1996, I 7:221-232.

18. Power C, Matthews S: Origins of health inequalities in a national population sample. Lancet 1997, 350: I584-9.

19. Kuh DJ, Wadsworth ME: Physical health status at $\mathbf{3 6}$ years in a British national birth cohort. Soc Sci Med 1993, 37:905-9|6.

20. Lundberg $O$ : The impact of childhood living conditions on illness and mortality in adulthood. Soc Sci Med 1993 , 36: $1047-1052$.

21. PJ MM, Davey SG, Hart CL, Gunning-Schepers LJ: Socioeconomic differentials in mortality among men within Great Britain: time trends and contributory causes. I Epidemiol Community Health 1998, 52:214-218.

22. Pietila $A M$, Jarvelin MR: Health and social standing of young men viewed in light of information on their childhood and adolescence. Int J Nurs Stud 1995, 32:545-555.

23. Rahkonen O, Lahelma E, Huuhka M: Past or present? Childhood living conditions and current socioeconomic status as determinants of adult health. Soc Sci Med 1997, 44:327-336.

24. Bosma H, Schrijvers C, Mackenbach JP: Socioeconomic inequalities in mortality and importance of perceived control: cohort study. BMJ 1999, 3 19:|469-|470.

25. Power $C$, Manor O: Explaining social class differences in psychological health among young adults: a longitudinal perspective. Soc Psychiatry Psychiatr Epidemiol 1992, 27:284-29I.

26. Elder G: Children of the Great Depression Chicago, University of Chicago Press; 1974: I-444.

27. Eichorn DH, Clausen IA, Haan N, Honzik MMP, P.H. M: Present and past in middle life New York, Academic Press; 198I: I-500.

28. Liker JK, Elder GHJ: Economic hardship and marital relations in the 1930s. American Sociological Review 1983, 4:343-359.

29. Barling J, Zacharatos A, Hepburn CG: Parents' job insecurity affects children's academic performance through cognitive difficulties. J Appl Psychol 1999, 84:437-444.

30. Barling J, Dupre KE, Hepburn CG: Effects of parents' job insecurity on children's work beliefs and attitudes. J Appl Psychol I998, 83: II2-II8.

31. MacEwan KE, Barling J: Effects of maternal employment experiences on children's behavior via mood, cognitive difficulties, and parenting behavior. Journal of Marriage and Family 1991, 53:635-644.

32. Hertzman C, Teschke K, Ostry A, Hershler R, Dimich-Ward H, Kelly S, Spinelli JJ, Gallagher RP, McBride M, Marion SA: Mortality and cancer incidence among sawmill workers exposed to chlorophenate wood preservatives. Am J Public Health 1997, 87:7I-79.

33. Ostry AS, Marion SA, Demers PA, Hershler R, Kelly S, Teschke K Hertzman $C$ : Measuring psychosocial job strain with the job content questionnaire using experienced job evaluators. $\mathrm{Am}$ I Ind Med 200I, 39:397-40I.

34. Ostry A, Marion SA, Green L, Demers PA, Hershler R, Kelly S, Teschke K, Mustard C, Hertzman C: Comparison of Expert-rater Methods for Assessing Psychosocial Job Strain. Scandinavian Journal of Work Environment and Health 2001, 27:1-6.

35. Dimich-Ward H, Hertzman C, Teschke K, Hershler R, Marion SA Ostry A, Kelly S: Reproductive effects of paternal exposure to chlorophenate wood preservatives in the sawmill industry. Scand J Work Environ Health 1996, 22:267-273. 
36. Dudley M, Kelk N, Florio T, Waters B, Howard J, Taylor D: Coroners' records of rural and non-rural cases of youth suicide in New South Wales. Aust N ZJ Psychiatry 1998, 32:242-25I.

37. Dudley MJ, Kelk NJ, Florio TM, Howard JP, Waters BG: Suicide among young Australians, 1964-1993: an interstate comparison of metropolitan and rural trends. Med J Aust 1998, 169:77-80.

38. Dudley M, Kelk N, Florio T, Howard J, Waters B, Haski C, Alcock M: Suicide among young rural Australians 1964- 1993: a comparison with metropolitan trends. Soc Psychiatry Psychiatr Epidemiol 1997, 32:25I-260.

39. Kelly S, Charlton J, Jenkins R: Suicide deaths in England and Wales, 1982-1992: The contribution of occupation and geography. Population Trends 1995, 80:16-25.

40. Mehlum L, Hytten K, Gjertsen F: Epidemiological trends of youth suicide in Norway. Archives of Suicide Research 1999, 5:193-205.

4I. Saunderson TR, Langford IH: A study of the geographical distribution of suicide rates in England and Wales $1989-92$ using empirical bayes estimates. Soc Sci Med 1996, 43:489-502.

\section{Pre-publication history}

The pre-publication history for this paper can be accessed here:

http://www.biomedcentral.com/1471-2458/6/77/prepub

Publish with Biomed Central and every scientist can read your work free of charge

"BioMed Central will be the most significant development for disseminating the results of biomedical research in our lifetime. "

Sir Paul Nurse, Cancer Research UK

Your research papers will be:

- available free of charge to the entire biomedical community

- peer reviewed and published immediately upon acceptance

- cited in PubMed and archived on PubMed Central

- yours - you keep the copyright

Submit your manuscript here:

http://www.biomedcentral.com/info/publishing_adv.asp 